\title{
Association of Medication Adherence with Hospital Utilization and Costs Among Elderly with Diabetes Enrolled in a State Pharmaceutical Assistance Program
}

\author{
Priti Pednekar, PhD, MPharm; Debra A. Heller, PhD, MPH; \\ and Andrew M. Peterson, PharmD, PhD, FCPP
}

\begin{abstract}
BACKGROUND: Medication adherence is crucial for the successful treatment among elderly patients with diabetes taking oral antidiabetic medications (0AMs). Cost of medications, lack of insurance coverage, and low income are major contributing factors towards medication nonadherence. State pharmaceutical assistance programs (SPAPs) provide medications at little or no cost to income-eligible patients and have potential to improve medication adherence among elderly patients. Despite this, limited research has focused on the association of medication adherence with health care utilization among elderly patients enrolled in SPAPs, and inclusion of health care costs as an outcome is even rarer.

OBJECTIVE: To evaluate the relationship between adherence to OAMs and hospital utilization and costs among elderly patients with diabetes who were enrolled in a SPAP.

METHODS: This retrospective observational study included elderly patients with diabetes enrolled in Pennsylvania's Pharmaceutical Assistance Contract for the Elderly (PACE) program in 2015. Medication adherence was estimated as the proportion of days covered (PDC; adherent: $P D C \geq 80 \%$, nonadherent: $\mathrm{PDC}<80 \%)$. Hospital utilization and costs were estimated using hospital discharge records from the Pennsylvania Health Care Cost Containment Council. Multiple adjusted regression analyses were used to examine the association of medication adherence with hospital utilization (all-cause and diabetes-related number of inpatient hospital visits and length of stay [LOS]) and costs.
\end{abstract}

RESULTS: Among 9,497 elderly PACE enrollees with diabetes, $81 \%$ were adherent, and $21 \%$ were hospitalized. Compared with adherent patients, patients who were nonadherent to OAMs had twice the odds of all-cause and diabetes-related hospitalization. Controlling for covariates, nonadherent patients had $27 \%$ more all-cause $(95 \% \mathrm{Cl}=9 \%-36 \%)$ and $21 \%$ more diabetes-related $(95 \% \mathrm{Cl}=5 \%-40 \%)$ hospital visits than adherent patients. Covariate-adjusted LOS for nonadherent patients was $24 \%$ longer than that of adherent patients for all-cause hospitalization $(95 \% \mathrm{Cl}=1.171-1.311)$ and $12.7 \%$ longer for diabetes-related hospitalization (95\% $\mathrm{Cl}=1.036-1.227)$. Medication nonadherence was associated with significantly greater all-cause $(\$ 22,670$ vs. $\$ 16,383 ; P<0.0001)$ and diabetes-related $(\$ 13,518$ vs. $\$ 12,634 ; P=0.0003)$ hospitalization costs.

CONCLUSIONS: Among SPAP-enrolled elderly patients, nonadherence to OAMs was significantly associated with increased risk of hospitalization, longer hospital stays, and greater hospitalization costs. Attention is needed to improve medication adherence among elderly receiving financial assistance to pay their prescriptions to reduce economic burden on the health care system.

J Manag Care Spec Pharm. 2020;26(9):1099-108

Copyright $\odot 2020$, Academy of Managed Care Pharmacy. All rights reserved.

\section{What is already known about this subject}

Previous research among patients with diabetes supports the link between medication adherence and lower health care utilization and costs.

Elderly patients find medication adherence challenging for several reasons, but cost of prescription medications is a major barrier to medication adherence.

- State pharmaceutical assistance programs (SPAPs) provide financial assistance to elderly patients for the purchase of prescription medications.

\section{What this study adds}

This study included residence in a pharmacy desert, representing low geographic accessibility to a nearby pharmacy, as one of the predictors, while studying the association of medication adherence with health outcomes.

Compared with earlier studies of SPAP-enrolled elderly patients with diabetes, different and more health care utilization and costs variables were analyzed, such as all-cause and diabetes-specific number of inpatient visits, length of inpatient stay, and hospitalization costs

This study adds new evidence and extends the current literature on medication adherence and health outcomes among elderly SPAP beneficiaries with diabetes.

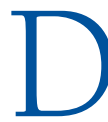
iabetes is one of the most prevalent chronic diseases that is responsible for increased mortality and morbidity in the United States. ${ }^{1,2}$ Total cost of the disease in 2017 was estimated to be $\$ 327$ billion, including $\$ 237$ billion of direct medical costs and $\$ 90$ billion due to decreased productivity. ${ }^{3}$ Prevalence of diabetes increases with age, and as of $2015,25.2 \%$ (about 12 million) of the population who were 65 years and older had diabetes. ${ }^{4}$

The majority of elderly patients with diabetes fail to achieve optimal glycemic control with diet, exercise, and lifestyle changes and require oral antidiabetic medications (OAMs). ${ }^{5}$ Medication adherence is crucial for successful treatment among elderly patients taking OAMs. ${ }^{6}$ Results of higher adherence to OAMs include improved glycemic control, reduced 


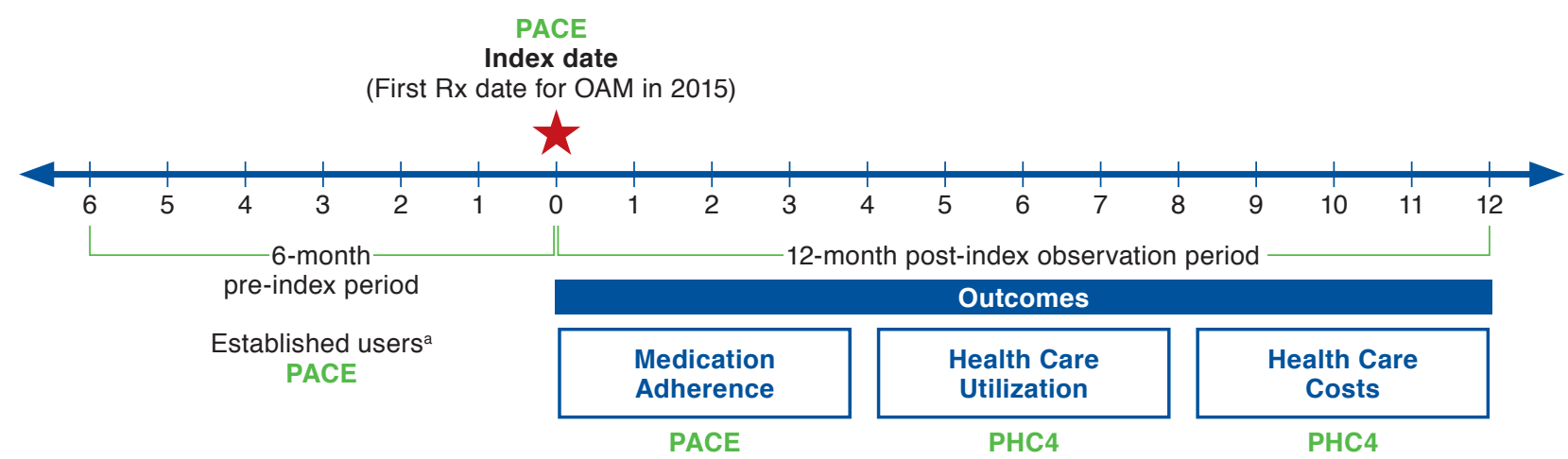

${ }^{a}$ Had at least 1 prescription fill for an OAM during the 6-month period before the index date.

$O A M=$ oral antidiabetic medication; PACE = Pharmaceutical Assistance Contract for the Elderly; PHC4=Pennsylvania Health Care Cost Containment Council; $R x=$ prescription.

diabetes-related complications, improved quality of life, lower risk of premature death, fewer emergency department visits, fewer hospitalizations, and reduced medical costs. ${ }^{7-10}$ Despite the importance of medication adherence, nonadherence to OAMs represents a substantial problem in the United States, with medication adherence rates ranging from 36\% to 59\% among elderly patients with diabetes. ${ }^{11,12}$ In 2007, the Centers for Medicare \& Medicaid Services (CMS) developed a star ratings system to evaluate the performance of Medicare Advantage and Prescription Drug (Part D) plans, and adherence to diabetes medications is one of the metrics used to calculate the star rating. ${ }^{13-15}$ Medicare plan sponsors use star ratings to qualify for quality bonus payments, to maintain or increase beneficiary enrollment, and to avoid termination by CMS. ${ }^{16}$ Hence, adherence to OAMs is a matter of great importance to all stakeholders-patients, health care providers, policymakers, and insurance plan sponsors.

There are several reasons why elderly patients do not follow their prescriptions. ${ }^{17,18}$ The cost of medications has been identified as a major contributing factor to medication nonadherence. ${ }^{19,20}$ Approximately 1 in 10 adults and $4.4 \%$ of elderly patients in the United States do not consume medications as prescribed because they cannot afford it. ${ }^{21}$ Patients with low income and limited or no prescription drug coverage are more likely to be nonadherent because of the cost burden. ${ }^{22,23}$ State pharmaceutical assistance programs (SPAPs) provide medications at little or no cost to income-eligible patients. Nearly all U.S. individuals aged 65 years and older are enrolled in Medicare. However, Medicare Part B does not pay for outpatient medications. In addition, not all elderly individuals are eligible for Medicaid, which provides prescription coverage. Consequently, SPAPs were implemented to help non-Medicaid low-income elderly patients. ${ }^{24}$ Since Medicare Part D was implemented in 2006, the role of many SPAPs has evolved to provide benefits that are coordinated with Part D prescription coverage.

Although there is growing evidence that medication adherence helps to improve health outcomes and reduce health care costs, ${ }^{25-31}$ limited research has focused on the association between medication adherence and health care utilization among elderly SPAP enrollees, and inclusion of health care costs as an outcome is even rarer. ${ }^{32}$ Hence, the objective of this study was to evaluate the relationship of medication adherence to hospital utilization and costs among elderly patients enrolled in a SPAP.

\section{Methods}

\section{Study Design and Data Sources}

A retrospective observational study using electronic databases for elderly patients enrolled in a Pennsylvania SPAP was conducted (Figure 1). This study used data from January 1, 2015, through December 31, 2016, the most recent data available at the time of analysis. The databases consisted of (a) cardholder data and prescription claims data from the Pharmaceutical Assistance Contract for the Elderly (PACE) program and (b) The Pennsylvania Health Care Cost Containment Council's (PHC4) hospital discharge data, which were linked to PACE data. PACE is a SPAP that provides low-cost prescription medications to more than 250,000 income-eligible Pennsylvania residents aged 65 years or older. During the study period, PACE's income limits were $\$ 23,500$ for single individuals and $\$ 31,500$ for married persons. PHC4 is an independent state agency that collects, analyzes, and disseminates hospital data in order to improve health care for Pennsylvanians. PHC4 collects data on more than 1.7 million inpatient discharges from Pennsylvania hospitals each year. ${ }^{33,34}$ 
Data on patient characteristics and dispensed prescriptions were obtained from PACE's cardholder and pharmacy claims files. Prescription data provided by PACE included claims paid directly by PACE, as well as supplemental prescription drug event data from Medicare Part D plans partnering with PACE to provide integrated Part D and SPAP benefits. Information on hospitalizations, length of stay, and associated costs were extracted from the PHC4 hospital discharge database. This study was approved by the Institutional Review Board of the University of the Sciences in Philadelphia.

The index date for each eligible patient was defined as the first prescription fill date for an OAM in 2015. Medication adherence, hospital utilization, and costs were evaluated during a fixed 12-month observation period including and following the index date. Because previous research suggests that medication adherence may be higher during the initial treatment period than during ongoing treatment, this study adopted a prevalent user approach. ${ }^{35,36}$ With this approach, only established users (defined as patients who had at least 1 fill for an OAM during the 6-month period preceding their 2015 index date) were included.

\section{Study Population}

Individuals who met the following criteria were included in this study:

- Had at least 12 months of continuous enrollment in PACE between their index fill dates and December 31, 2016.

- Were alive throughout the 12-month post-index observation period.

- Were either not enrolled in Medicare Part D or had Part D coverage with a Medicare Part D plan partnering with PACE. Individuals with Part D coverage through nonpartner plans were excluded, which ensured that a complete record of all prescriptions paid for by either PACE or Part D was available for analysis.

- Had at least 2 prescription claims for OAMs in 2015. Although we were unable to verify a diagnosis of diabetes because of the lack of health care data before PACE enrollment, patients meeting the study's OAM prescription criteria would generally be expected to receive long-term treatment for diabetes.

Because methods used for calculating adherence for nonoral and oral medications differ, ${ }^{37,38}$ adherence measurements of patients using non-OAMs may not be directly comparable with those of patients using only OAMs. Therefore, patients using non-OAMs with or without OAMs were excluded.

A pharmacy desert represents low geographic accessibility to a nearby community pharmacy, which may create disparities across communities in access to prescription medications and thereby medication adherence. ${ }^{39}$ To control for potential pharmacy desert effects, a dichotomous measure of residence within a pharmacy desert was included as a covariate. Because pharmacy desert status is based on the distance between a patient's residence and a nearby pharmacy, ${ }^{39}$ which assumes that individuals obtain prescriptions as walk-in patients, individuals who had any mail-order prescription claims were excluded. Similarly, individuals who resided in nursing homes or other long-term care settings during the observation period were excluded. Since this study was evaluated from a payer's perspective, patients whose hospitalizations during the observation period were paid for by non-Medicare payers were also excluded.

\section{Medication Adherence Measurement}

Adherence to OAMs was calculated as the proportion of days covered (PDC) using prescription claims data. PDC is a widely used and well-accepted standard measure to evaluate medication adherence in various diseases and is the adherence measure preferred by the Pharmacy Quality Alliance (PQA). ${ }^{37,40,41}$ PDC was defined as the percentage of days during the 12-month post-index observation period that the patient had at least 1 OAM available. ${ }^{42}$ The formula used to calculate $\mathrm{PDC}$ is illustrated by the following equation:

$$
\begin{gathered}
\text { PDC }=(\text { Number of days in the } 12 \text {-month post-index } \\
\text { observation period when at least } 1 \text { OAM } \\
\text { was available } \div 365) \times 100
\end{gathered}
$$

The "at least 1" definition of PDC takes into account overlapping prescriptions, changes in therapeutic regimen, and use of concurrent medications. This measurement strategy is recommended by PQA and has been widely used by other researchers. ${ }^{41,43-45}$ Patients were categorized as "adherent" if PDC was $\geq 80 \%$ and "nonadherent" if PDC was $<80 \%$, consistent with the dichotomization of medication adherence used in previous studies. ${ }^{27,46-49}$ This dichotomous adherence measure was used as the primary predictor variable in the multivariable analyses.

\section{Health Care Utilization and Costs Measures}

The primary outcome evaluated to measure hospital utilization was risk of hospitalization (whether a patient had 1 or more inpatient hospitalizations) during the 12-month post-index observation period. Secondary utilization measures included the number of hospital visits and length of stay (LOS) in days associated with inpatient hospitalization during the 12-month post-index observation period. While calculating these measures, 2 types of inpatient hospitalizations were considered: all-cause and diabetes-related. All-cause hospitalization was defined as an inpatient hospitalization for any reason. Diabetes-related hospitalization was defined as an inpatient hospitalization with International Classification of Diseases, Ninth Revision, Clinical Modification codes (250.X0 and 250.X2, $\mathrm{X}=0-9)$ or International Classification of Diseases, Tenth Revision, Clinical Modification codes (E11 and E13) and with diagnosis 
TABLE 1 Patient Characteristics by Adherence Status ${ }^{a}(N=9,497)$

\begin{tabular}{|c|c|c|c|c|c|}
\hline \multirow[b]{2}{*}{ Characteristics } & \multicolumn{2}{|c|}{$\begin{array}{c}\text { Adherent } \\
(\mathrm{PDC} \geq 80 \%) \\
(\mathrm{n}=7,696)\end{array}$} & \multicolumn{2}{|c|}{$\begin{array}{l}\text { Nonadherent } \\
\text { (PDC }<80 \%) \\
(\mathrm{n}=1,801)\end{array}$} & \multirow[b]{2}{*}{$P$ Value ${ }^{b}$} \\
\hline & $\mathrm{N}$ or mean & $\%$ or SD & $\mathrm{N}$ or mean & $\%$ or $\mathrm{SD}$ & \\
\hline Age, years (mean and SD) & 79.82 & 6.83 & 79.85 & 7.10 & 0.8659 \\
\hline \multicolumn{6}{|l|}{ Sex } \\
\hline Male & 2,105 & 27.35 & 516 & 28.65 & \multirow{2}{*}{0.2670} \\
\hline Female & 5,591 & 72.65 & 1,285 & 71.35 & \\
\hline \multicolumn{6}{|l|}{ Race } \\
\hline White & 6,989 & 90.81 & 1,541 & 85.56 & \multirow{4}{*}{$<0.0001$} \\
\hline African American & 305 & 3.96 & 117 & 6.50 & \\
\hline Other & 81 & 1.05 & 28 & 1.55 & \\
\hline Unknown & 321 & 4.17 & 115 & 6.39 & \\
\hline \multicolumn{6}{|l|}{ Ethnicity } \\
\hline Hispanic & 100 & 1.30 & 41 & 2.28 & \multirow{2}{*}{0.0020} \\
\hline Non-Hispanic & 7,596 & 98.70 & 1,760 & 97.72 & \\
\hline \multicolumn{6}{|l|}{ Annual income, 2014 U.S. dollars } \\
\hline$<\$ 5,000$ & 108 & 1.40 & 37 & 2.05 & \multirow{5}{*}{0.3145} \\
\hline$\$ 5,000-\$ 9,999$ & 552 & 7.17 & 125 & 6.94 & \\
\hline$\$ 10,000-\$ 14,999$ & 2,367 & 30.76 & 567 & 31.48 & \\
\hline$\$ 15,000-\$ 19,999$ & 2,532 & 32.90 & 579 & 32.15 & \\
\hline$\geq \$ 20,000$ & 2,137 & 27.77 & 493 & 27.37 & \\
\hline \multicolumn{6}{|l|}{ Marital status } \\
\hline Single/widowed & 4,996 & 64.92 & 1,144 & 63.52 & \multirow{4}{*}{0.2956} \\
\hline Married & 1,811 & 23.53 & 461 & 25.60 & \\
\hline Divorced & 716 & 9.30 & 156 & 8.66 & \\
\hline Married but living separately & 173 & 2.25 & 40 & 2.22 & \\
\hline \multicolumn{6}{|l|}{ Lived in a pharmacy desert } \\
\hline Yes & 3,559 & 46.24 & 785 & 43.59 & \multirow{2}{*}{0.1225} \\
\hline No & 3,935 & 51.13 & 968 & 53.75 & \\
\hline Total number of unique medications ${ }^{\mathrm{c}}$ (mean and SD) & 10.53 & 4.54 & 10.26 & 4.96 & 0.0327 \\
\hline OPP (mean and SD) & 8.12 & 10.13 & 7.39 & 11.03 & 0.0099 \\
\hline \multicolumn{6}{|l|}{ Medication adherence } \\
\hline PDC (mean and SD) & 94.87 & 5.15 & 58.74 & 17.24 & \multirow{2}{*}{$<0.0001$} \\
\hline PDC (median and IQR) & 96.00 & 7.00 & 64.00 & 24.00 & \\
\hline
\end{tabular}

${ }^{a}$ Differences in continuous variables were examined using t-tests, and differences in categorical variables were examined using chi-square tests.

bStatistically significant if $P<0.05$.

'Total number of unique medications based on unique classes of medications on hand for any disease during the 12-month post-index observation period for a patient. HIC3 classification was used to determine class of the medication.

HIC3 = Hierarchical Ingredient Code Level 3; IQR=interquartile range; $O P P=$ out-of-pocket payment; $P D C=$ proportion of days covered; $S D=$ standard deviation .

codes reflecting diabetes-related complications, which was adapted from the American Diabetes Association's study of U.S. economic costs of diabetes. ${ }^{3}$

Hospitalization cost included only direct medical costs related to inpatient hospitalization, since this study adopted a third-party payer (Medicare) perspective. Direct nonmedical and indirect medical costs were not included. Direct inpatient hospitalization cost was the sum of room and board costs, ancillary costs, drug costs, equipment costs, specialty costs, miscellaneous costs, and professional fees. Costs were calculated from total charges using hospital-level, Medicare-specific, cost-to-charge ratios for the year of hospitalization (2015 or
2016). All costs were converted to 2015 U.S. dollars using the medical component of the Consumer Price Index. Costs were calculated separately for all-cause and diabetes-related hospitalizations.

\section{Covariates or Other Variables}

Patient-level sociodemographic measures, including age, sex, race, ethnicity, annual income, and marital status, were obtained from PACE's cardholder database. Patients were categorized as residing in a pharmacy desert or not, using the classification of pharmacy deserts developed in an earlier study. ${ }^{50}$ The total number of unique medications based on First 
TABLE 2 Unadjusted Health Care Utilization and Costs Among the Study Population During the 12-Month Post-Index Observation Period, Overall and by Adherence Status ${ }^{\mathrm{a}}(\mathrm{N}=9,497)$

\begin{tabular}{|c|c|c|c|c|c|c|c|}
\hline $\begin{array}{l}\text { Health Care } \\
\text { Utilization/Cost Variable }\end{array}$ & \multicolumn{2}{|c|}{$\begin{array}{c}\text { All } \\
(\mathrm{N}=9,497)\end{array}$} & \multicolumn{2}{|c|}{$\begin{array}{c}\text { Adherent } \\
(\text { PDC } \geq 80 \%) \\
(\mathrm{n}=7,696)\end{array}$} & \multicolumn{2}{|c|}{$\begin{array}{c}\text { Nonadherent } \\
\text { (PDC < 80\%) } \\
(\mathrm{n}=1,801)\end{array}$} & $P$ Value ${ }^{b}$ \\
\hline \multicolumn{8}{|c|}{ Number of inpatient hospital visits per 100 persons (SD) } \\
\hline All-cause & 34 & $(0.83)$ & 29 & $(0.73)$ & 54 & $(1.14)$ & $<0.0001$ \\
\hline Diabetes-related & 10 & $(0.40)$ & 9 & $(0.37)$ & 15 & $(0.50)$ & $<0.0001$ \\
\hline \multicolumn{8}{|c|}{ Length of stay in days, mean (SD) } \\
\hline All-cause & 1.80 & $(5.82)$ & 1.45 & $(4.78)$ & 3.31 & $(8.85)$ & $<0.0001$ \\
\hline Diabetes-related & 0.43 & $(2.14)$ & 0.36 & $(1.89)$ & 0.71 & $(2.97)$ & $<0.0001$ \\
\hline \multicolumn{8}{|c|}{ Costs of inpatient hospitalizations, mean (SD)c } \\
\hline All-cause & $\$ 3,767$ & $(\$ 12,342)$ & $\$ 3,077$ & $(\$ 10,250)$ & $\$ 6,716$ & $(\$ 18,538)$ & $<0.0001$ \\
\hline Diabetes-related & $\$ 965$ & $(\$ 5,073)$ & $\$ 847$ & $(\$ 4,683)$ & $\$ 1,468$ & $(\$ 6,455)$ & 0.0001 \\
\hline \multicolumn{8}{|c|}{$\begin{array}{l}\text { aDifferences between adherent and nonadherent patients were examined using t-tests. } \\
\text { bStatistically significant if } P<0.05 \text {. } \\
\text { cPresented in } 2015 \text { U.S. dollars. } \\
P D C=\text { proportion of days covered; } S D=\text { standard deviation. }\end{array}$} \\
\hline
\end{tabular}

DataBank's Hierarchical Ingredient Code Level 3 classification filled during the 12-month post-index observation period (regardless of whether they were used to treat diabetes) was used as a proxy measure for disease burden..$^{27,46,49,51}$ For each patient, the out-of-pocket payment per OAM prescription was calculated by dividing the sum of all PACE copayments, Part D premiums collected by PACE against drug cost at the point of sale, and patient pay amounts (for Part D claims that were not also submitted to PACE) by the total number of OAM prescriptions filled during the 12-month post-index observation period.

\section{Statistical Analysis}

Descriptive statistics for the study sample were reported. For unadjusted analyses, Student's t-tests for continuous variables and chi-square tests for categorical variables were used to compare the adherent and nonadherent groups. Multivariable logistic regression was used to evaluate the association between medication adherence and hospitalization, while adjusting for sociodemographic characteristics, pharmacy desert residence, number of unique medications, and out-of-pocket payment. Odds ratios and 95\% confidence intervals (CIs) were reported.

The relationship between medication adherence and hospital utilization (number of hospital visits and LOS) was evaluated using separate covariate-adjusted zero-inflated negative binomial regression (ZINB) analyses. ZINB regression analysis is appropriate when count data (e.g., number of hospital visits and LOS) show a very skewed distribution and overdispersion and exhibit many zero count observations. ${ }^{52}$ Comparison of the ZINB and negative binomial models was performed using the Vuong test, which indicated that the ZINB model exhibited a significantly better fit to the data. Incidence rate ratios (IRRs) and 95\% CIs were reported for ZINB models. The IRR represents the rate of hospital utilization during the observation period in nonadherent compared with adherent patients.

Two-part models were used to examine the association of medication adherence with hospitalization $\operatorname{costs}^{53}$; the first part captured the probability of an all-cause or diabetes-related inpatient hospitalization, and the second part used general linear models with a gamma distribution and log link function to estimate costs, while controlling for covariates. Predicted cost estimates and corresponding 95\% CIs based on generalized linear models, and corresponding $P$ values based on t-tests, were reported.

All statistical analyses were conducted using SAS software, version 9.4 (SAS Institute, Cary, NC).

\section{Results}

\section{Study Population}

Overall, $81 \%$ of patients were adherent $(n=7,696)$, and $19 \%$ of patients were identified as nonadherent ( $\mathrm{n}=1,801$; Table 1$)$. Adherent patients were more likely to be White (90.81\% vs. 85.56\%; $P<0.0001)$ and non-Hispanic $(98.70 \%$ vs. $97.72 \%$; $P=0.0020)$ compared with nonadherent patients. Adherent patients filled prescriptions for more unique medications (10.53 vs. 10.26; $P=0.0327$ ), paid higher out-of-pocket payments ( $\$ 8.12$ vs. $\$ 7.39 ; P=0.0099$ ), and had greater average PDC (95\% vs. 59\%) compared with nonadherent patients. No significant differences were observed between adherent and nonadherent patients for age, sex, annual income, marital status, and pharmacy desert status.

\section{Unadjusted Health Care Utilization and Costs}

A significantly greater proportion of nonadherent patients had at least 1 all-cause ( $29 \%$ vs. $18.8 \%$; $P<0.0001)$ or diabetes-related (10.7\% vs. $6.7 \% ; P<0.0001$ ) inpatient hospitalization during 


\begin{tabular}{|c|c|c|c|c|c|c|}
\hline \multirow{2}{*}{$\begin{array}{l}\text { Type of Inpatient } \\
\text { Hospital Visit }\end{array}$} & \multicolumn{2}{|c|}{ Risk of Hospitalization } & \multicolumn{2}{|c|}{ Hospital Visits } & \multicolumn{2}{|c|}{ LOS (in days) } \\
\hline & Adjusted OR ${ }^{a}$ & $95 \% \mathrm{CI}$ & Adjusted IRR ${ }^{b}$ & $95 \% \mathrm{CI}$ & Adjusted IRR ${ }^{b}$ & $95 \% \mathrm{CI}$ \\
\hline All-cause & 2.020 & $1.776-2.297$ & 1.2676 & $1.1894-1.3510$ & 1.2393 & $1.1713-1.3112$ \\
\hline Diabetes-related & 1.750 & $1.455-2.103$ & 1.2012 & $1.0404-1.3869$ & 1.1280 & $1.0369-1.2271$ \\
\hline \multicolumn{7}{|c|}{$\begin{array}{l}\text { Note: Adjusted for predefined covariates: age, sex, race, ethnicity, income, marital status, pharmacy desert, number of unique medications, and out-of-pocket payments. } \\
\text { aOdds ratio for nonadherence versus adherence. } \\
\text { bIncidence rate ratio for nonadherence versus adherence. } \\
C I=\text { confidence interval; LOS = length of stay; SPAP = state pharmaceutical assistance program. }\end{array}$} \\
\hline
\end{tabular}

the observation period than adherent patients (Appendix A, available in online article). The number of inpatient hospital visits per 100 persons was 34 for all-cause and 10 for diabetesrelated admissions (Table 2). The average LOS for hospitalized patients was nearly 2 days for all-cause hospitalization and approximately one-half day for diabetes-related complications. Average annual inpatient costs for all-cause and diabetesrelated hospitalizations were $\$ 3,767$ and $\$ 965$, respectively.

Table 2 also shows hospital utilization and costs by adherence status. Adherent patients had significantly fewer all-cause ( 29 vs. $54 ; P<0.0001$ ) and diabetes-related (9 vs. $15 ; P<0.0001)$ inpatient hospital visits compared with nonadherent patients. Similarly, adherent patients had significantly shorter LOS for all-cause (1.45 vs. 3.31; $P<0.0001)$ and diabetes-related (0.36 vs. $0.71 ; P<0.0001)$ hospitalizations than nonadherent patients. Inpatient cost was significantly higher for nonadherent patients than for adherent patients (mean $\$ 6,716$ vs. $\$ 3,077 ; P<0.0001)$. Similarly, nonadherent patients had significantly higher diabetes-related hospitalization cost than adherent patients (mean $\$ 1,468$ vs. $\$ 847 ; P=0.0001$ ).

Among patients who had at least 1 inpatient hospital admission during the 12-month post-index observation period, the number of admissions per 100 persons was 164 for all-cause hospitalization and 48 for diabetes-related hospitalization (Appendix B, available in online article). Average LOS among hospitalized patients was 9 days for all-cause hospitalizations and 2 days for diabetes-related hospitalizations. Hospitalized patients incurred average costs of $\$ 18,066$ and $\$ 4,623$ for all-cause and diabetes-related hospitalizations, respectively. The number of all-cause hospitalizations per 100 persons was significantly lower for adherent patients than for nonadherent patients (156 vs. 188; $P<0.0001$ ). However, the difference in number of diabetes-related hospitalizations per 100 persons between adherent and nonadherent patients was not statistically significant ( 47 vs. $51 ; P=0.2518$ ). The annual average LOS for all causes was significantly lower for adherent patients than nonadherent patients (7.70 vs. $11.41 ; P<0.0001)$. Similarly, average LOS for diabetes-related hospitalizations was significantly shorter for adherent patients compared with nonadherent patients (1.91 vs. 2.47; $P=0.0254$ ). Among hospitalized patients, significantly greater all-cause hospitalization cost was observed in nonadherent patients compared with adherent patients (mean $\$ 23,059$ vs. $\$ 16,266 ; P<0.0001$ ). However, no significant difference was observed for diabetes-related hospitalization costs among adherent and nonadherent hospitalized patients $(P=0.3179)$.

\section{Relationship of Medication Adherence with Hospital Utilization}

Regression analyses suggested a negative association between adherence and likelihood of hospitalization (Table 3). When adjusted for predefined covariates, the odds of being hospitalized for all-cause and diabetes-related complications were $2.020(95 \% \quad C I=1.776-2.297 ; \quad P<0.0001)$ and 1.750 (95\% CI = 1.455-2.103; $P<0.0001$ ), respectively, for nonadherent patients compared with adherent patients. Nonadherent patients also had significantly greater hospital utilization than adherent patients, when adjusted for baseline characteristics. Controlling for covariates, nonadherent patients had $27 \%$ more all-cause (IRR $=1.2676 ; 95 \% C I=1.1894-1.3510$; $P<0.0001)$ and $20 \%$ more diabetes-related (IRR $=1.2012 ; 95 \%$ $\mathrm{CI}=1.0404-1.3869 ; P=0.0124)$ hospital visits than adherent patients. Compared with adherent patients, covariate-adjusted LOS for nonadherent patients was $24.0 \%$ longer for all-cause $(\mathrm{IRR}=1.2393 ; 95 \% \mathrm{CI}=1.1713-1.3112 ; \mathrm{P}<0.0001)$ and $12.8 \%$ longer for diabetes-related (IRR $=1.1280$; 95\% CI $=1.0369$ 1.2271; $P=0.0051$ ) hospitalizations.

\section{Association of Medication Adherence with Hospitalization Costs}

When the association between adherence to OAMs and hospitalization costs among subjects who were hospitalized at least once during the observation period was analyzed, while adjusting for covariates, the predicted inpatient hospitalization cost was significantly lower for adherent than for nonadherent 
patients for all-cause ( $\$ 16,374$ vs. $\$ 22,697 ; P<0.0001)$ and diabetes-related hospitalization ( $\$ 12,659$ vs. $\$ 13,515 ; P=0.0039$; Figure 2). These findings indicate that adherence was associated with significant reductions in health care costs.

\section{Discussion}

This study aimed to provide real-world evidence of the relationship of adherence to OAMs with inpatient hospital utilization and costs among the elderly enrolled in a SPAP. Compared with adherent patients, those who were nonadherent to OAMs had approximately twice the odds of all-cause and diabetes-related hospitalizations. Nonadherent patients also had significantly more inpatient hospital visits and longer LOS than adherent patients. A negative relationship between medication adherence and health care utilization was observed for all-cause and diabetes-related inpatient hospitalizations. Among the elderly with at least 1 hospitalization, patients who were adherent to OAMs had lower all-cause and diabetes-related inpatient hospitalization costs than nonadherent patients. Adherence-based reductions in hospitalization costs appeared to be driven primarily by lower hospitalization rates among adherent patients.

These findings are consistent with earlier literature indicating that medication nonadherence is associated with greater risk of hospitalization, greater health care utilization, and higher health care costs. ${ }^{6,26,27,29,30,54-60}$ Lau et al. (2004) and Ho et al. (2008) reported that the odds of being hospitalized were 2.53 and 1.58 , respectively, for nonadherent patients compared with patients adherent to OAMs. ${ }^{54,61}$ Curtis et al. (2017) demonstrated that among type 2 diabetes patients, nonadherent individuals ( $\mathrm{PDC}<80 \%$ ) were significantly more likely to be hospitalized ( $22.71 \%$ vs. $17.65 \%$ ), had significantly more hospitalizations (mean 0.40 vs. 0.27 ), and had longer LOS (mean 2.16 vs. 1.25 days) compared with adherent individuals (PDC $\geq 80 \%$ ). ${ }^{55}$ Roebuck et al. (2011) reported average annual medical savings of $\$ 4,413$ due to adherence among patients with diabetes. ${ }^{56}$

Very few studies have reported the linkage of medication adherence with health care utilization and costs among elderly SPAP participants. ${ }^{32}$ A 2010 study of PACE cardholders by Ding found that adherence across multiple medication classes, including OAM, was associated with lower hospital utilization. $^{32}$ That study, however, only examined all-cause hospitalization and used a different methodological approach by evaluating the effect of PDC separately for persistent and nonpersistent medication users. In addition, the study did not consider out-of-pocket drug costs or pharmacy desert residence. Hence, the present study adds new evidence and extends the current literature on medication adherence and health care utilization and costs among elderly SPAP beneficiaries with diabetes.

The finding that OAM adherence is associated with significantly lower hospital utilization and cost has important
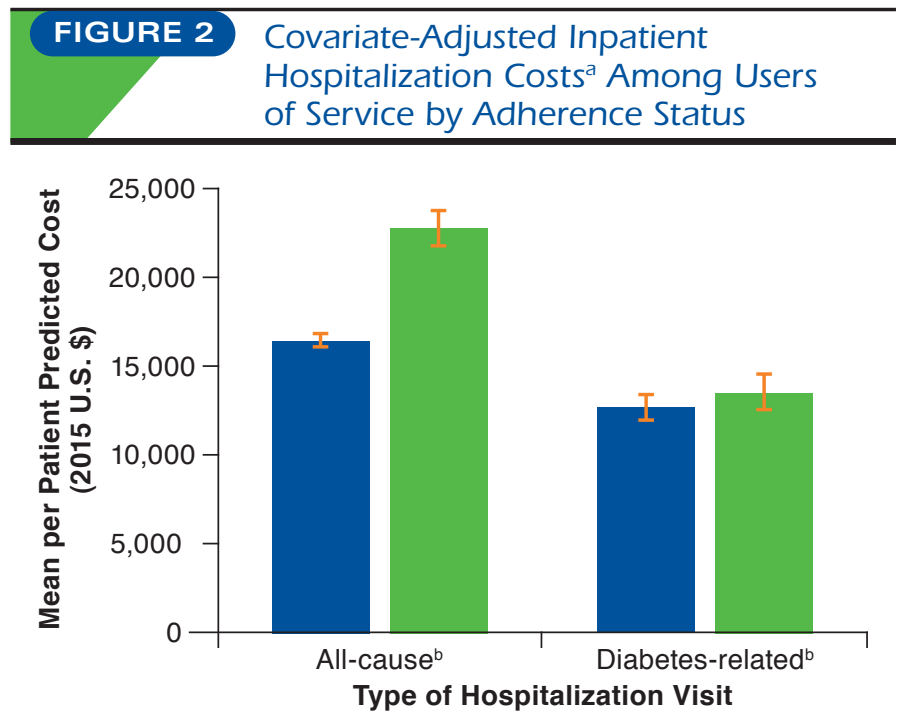

Adherent $(\mathrm{PDC} \geq 80 \%) \quad$ Nonadherent $(\mathrm{PDC}<80 \%)$

\begin{tabular}{l|c|c}
\hline & $\begin{array}{c}\text { All-Cause } \\
(\mathbf{n}=\mathbf{1}, 907)\end{array}$ & $\begin{array}{c}\text { Diabetes-Related } \\
(\mathbf{n}=708)\end{array}$ \\
\hline $\begin{array}{l}\text { Adherent, mean } \\
(95 \% \mathrm{CI})\end{array}$ & $\begin{array}{c}\$ 16,374 \\
\$ 12,659\end{array}$ \\
\hline $\begin{array}{l}\text { Nonadherent, mean } \\
(95 \% \mathrm{CI})\end{array}$ & $\$ 16,176-\$ 16,571)$ & $(\$ 12,348-\$ 12,970)$ \\
\hline
\end{tabular}

apredicted costs estimates and corresponding 95\% CIs based on generalized linear models, and corresponding $P$ values based on paired t-tests.

${ }^{b} \mathrm{P}<0.01$.

$C I=$ confidence interval $P D C=$ proportion of days covered .

implications for federal and state policymakers seeking to reduce health care costs. To realize the potential health care savings that may result from better medication adherence, policy solutions aimed at improving adherence are needed. Our findings emphasize the importance of increasing awareness about medication adherence and the need for earlier identification of poor adherence among SPAP-enrolled patients. Several existing policy efforts that may help to improve medication adherence are based on cost-related considerations, including efforts to increase the availability of cheaper alternative medications, expand insurance coverage, and increase access to prescription assistance programs such as PACE. Expanding access to SPAPs may provide benefits beyond states' direct cost sharing. For example, PACE facilitates enrollees' access to Medicare Part D and the Part D low-income subsidy. These coordinated benefits are reflected in the out-of-pocket costs analyzed in this study.

In addition to these considerations, future policy efforts should also focus on the role that SPAPs, pharmacists, and clinicians can have in educating patients about their health conditions and value of their drug therapy and in 
motivating behavioral changes to enhance medication adherence. Policymakers may encourage primary care providers and pharmacies to invest in adherence-enhancing resources, such as counseling services, through financial rewards. Pharmacistled patient counseling has been shown to increase medication adherence at less expense than the savings generated. ${ }^{56}$ Clinicians and pharmacists may also conduct routine assessments of medication nonadherence in elderly patients enrolled in a SPAP for the early identification of high-risk individuals. Such patients can be targeted with adherence-improving interventions.

\section{Limitations and Strengths}

This study has some limitations. First, this study was observational, so definite conclusions about causal relationships between adherence and hospital utilization and costs cannot be established. Second, this study examined the concurrent relationship between medication adherence and hospitalization outcomes during a 12-month post-index observation period. This approach cannot capture variations in adherence that may have altered the outcome at a different time.

Third, the study used a prevalent user design by including only established OAM users. Prevalent users may introduce spillover effects of prestudy adherence on outcomes measured during the study period. The prevalent user sample may have preferentially included patients who have been successful taking OAMs, thereby introducing a "healthy adherer" bias. ${ }^{62}$ Healthy adherer bias could also occur if OAM-adherent patients were more likely than nonadherent patients to have other healthy lifestyle behaviors. In addition, if OAM-adherent patients were similarly adherent to medications for other health conditions, then the positive outcomes associated with OAM adherence may be partially attributable to adherence to other medications. Controlling for healthy adherer effects was beyond the scope of this study.

Fourth, this study measured disease burden based on unique medications used during the observation period when medication adherence and outcomes were measured but did not include a baseline comorbidity measure. Future studies may consider comorbidity measurements in the period before the index fill date to estimate baseline disease burden.

Fifth, elderly patients who used insulin or other injections were excluded to avoid differences in the calculation of medication adherence. Insulin and other injections may be associated with greater disease severity. Hence, this study's findings may not be generalizable to all patients with diabetes. Further research is warranted to understand differences between insulin users and other OAMs users.

Sixth, the strategy of calculating PDC by evaluating whether "at least 1" OAM was available on a given day, while considered the optimal approach to PDC calculation, ${ }^{41}$ may overestimate adherence among patients prescribed multiple OAMs who must take all of the medications daily for a therapeutic benefit. ${ }^{42}$ In addition, claims-based adherence measures such as PDC may not reflect actual medication consumption. Claims data on hospitalizations often do not include information on inpatient medication use, so patients were assumed to be fully adherent to medications during inpatient hospitalizations. It is possible that patients received their daily medications while they were hospitalized, which may have delayed the filling of their prescriptions at a pharmacy.

Previous literature has shown that, on average, different approaches to handling hospitalizations yield adherence estimates that are similar to estimates that incorporate inpatient medication use, and adjustments to PDC are primarily required if patients were hospitalized for $>28$ days. ${ }^{63}$ In this study, only 15 of 9,497 patients were hospitalized for $>28$ days, hence, accounting for inpatient days would be expected to have minimal effect on the final PDC.

Finally, because of unavailability of data, this study could not identify additional assistance such as medication samples from physicians, which may have further reduced costs for patients.

Despite these limitations, this study has unique attributes and offers several important strengths. The study used a statewide comprehensive dataset of linked prescription and hospitalization records and reported noteworthy findings for SPAP-enrolled elderly patients with diabetes in a real-world setting. Medicare is the largest payer of health care in the United States, but it is facing decreased funding; therefore, understanding the factors associated with high risk and high users of Medicare-reimbursed services is critical.

This study is valuable in that it provides new evidence about high-risk elderly patients with diabetes who have higher hospital utilization and Medicare-covered costs. Additionally, the methodological approach of this study, which is based on the linkage of low-cost administrative databases, can be applied to other disease conditions and to other SPAPs to evaluate health outcomes and their economic burden on the U.S. health care system.

\section{Conclusions}

The results of this study indicated that, among elderly patients with diabetes who were enrolled in a SPAP, medication nonadherence was significantly associated with an increased risk of hospitalization, greater number of hospital visits, and longer hospital LOS. Consistent with these findings, nonadherence to OAMs was also associated with substantial hospitalization costs among hospitalized SPAP-enrolled elderly patients. These findings suggest that adherence to OAMs among older SPAPenrolled adults with diabetes may lead to significant benefits for patients without increasing health care resource use and Medicare costs. Application of adherence-enhancing interventions, as well as motivating and monitoring SPAP enrollees for medication adherence, should be a priority for SPAP administrators, particularly when value-based care is changing the health care landscape. 


\section{Authors}

PRITI PEDNEKAR, PhD, MPharm, PRECISIONheor, Los Angeles, California; DEBRA A. HELLER, PhD, MPH, Magellan Rx Management/PACE, Harrisburg, Pennsylvania; and ANDREW M. PETERSON, PharmD, PhD, FCPP, University of the Sciences, Philadelphia, Pennsylvania.

AUTHOR CORRESPONDENCE: Priti Pednekar, PhD, MPharm, PRECISIONheor, 11100 Santa Monica Blvd., Ste. 500, Los Angeles, CA 90025. Tel.: 267.438.3588; Email: priti.pednekar@precisionxtract.com.

\section{DISCLOSURES}

No outside funding supported this study. The authors have nothing to disclose.

\section{ACKNOWLEDGMENTS}

The authors thank the Pharmaceutical Assistance Contract for the Elderly (PACE) and the Pennsylvania Health Care Cost Containment Council (PHC4) for providing data for this study. PHC4 is an independent state agency responsible for addressing the problem of escalating health costs, ensuring the quality of health care, and increasing access to health care for all citizens regardless of ability to pay. PHC4 has provided data to the authors in an effort to further PHC4's mission of educating the public and containing health care costs in Pennsylvania. PHC4, its agents, and staff have made no representation, guarantee, or warranty, express or implied, that the data-financial-, patient-, payer-, and physician-specific information-provided are error-free or that the use of the data will avoid differences of opinion or interpretation. This analysis was not prepared by PHC4. This analysis was done by the authors. PHC4, its agents, and staff, bear no responsibility or liability for the results of the analysis, which are solely the opinion of the authors.

\section{REFERENCES}

1. Kochanek K, Murphy S, Xu J, Arias E. Deaths: final data for 2017. Natl Vital Stat Reports. 2019;68(9):1-15. Available at: https://www.cdc.gov/nchs/ data/nvsr/nvsr68/nvsr68_09-508.pdf. Accessed July 22, 2020.

2. Centers for Disease Control and Prevention. New CDC report: more than 100 million Americans have diabetes or prediabetes. Press release. July 18, 2017. Available at: https://www.cdc.gov/media/releases/2017/p0718-diabetesreport.html. Accessed July 22, 2020.

3. American Diabetes Association. Economic costs of diabetes in the U.S. in 2017. Diabetes Care. 2018;41(5):917-28.

4. Centers for Disease Control and Prevention. National diabetes statistics report, 2017. Available at: https://dev.diabetes.org/sites/default/files/2019-06/ cdc-statistics-report-2017.pdf. Accessed July 22, 2020.

5. Rizvi AA. Nutritional challenges in the elderly with diabetes. Int J Diabetes Mellit. 2009;1(1):26-31

6. Polonsky WH, Henry RR. Poor medication adherence in type 2 diabetes: recognizing the scope of the problem and its key contributors. Patient Prefer Adherence. 2016;10:1299-307.

7. DiBonaventura M, Wintfeld N, Huang J, Goren A. The association between nonadherence and glycated hemoglobin among type 2 diabetes patients using basal insulin analogs. Patient Prefer Adherence. 2014;8:873-82.

8. Han E, Suh D-C, Lee S-M, Jang S. The impact of medication adherence on health outcomes for chronic metabolic diseases: a retrospective cohort study. Res Social Adm Pharm. 2014;10(6):e87-98.
9. Egede LE, Gebregziabher M, Dismuke CE, et al. Medication nonadherence in diabetes: longitudinal effects on costs and potential cost savings from improvement. Diabetes Care. 2012;35(12):2533-39.

10. Capoccia K, Odegard PS, Letassy N. Medication adherence with diabetes medication. Diabetes Educ. 2016;42(1):34-71.

11. Kirkman MS, Rowan-Martin MT, Levin R, et al. Determinants of adherence to diabetes medications: findings from a large pharmacy claims database. Diabetes Care. 2015;38(4):604-09.

12. Patel I, Chang J, Shenolikar RA, Balkrishnan R. Medication adherence in low income elderly type-2 diabetes patients: a retrospective cohort study. Int J Diabetes Mellit. 2010;2(2):122-24.

13. Medicare Interactive. How to compare plans using the Medicare star rating system. Available at: https://www.medicareinteractive.org/getanswers/medicare-health-coverage-options/changing-medicare-coverage/ how-to-compare-plans-using-the-medicare-star-rating-system. Accessed July 22, 2020

14. American Pharmacists Association, Academy of Managed Care Pharmacy. Medicare star ratings: stakeholder proceedings on community pharmacy and managed care partnerships in quality. J Am Pharm Assoc. 2014;54(3):228-40.

15. Pharmacy Quality Alliance. PQA measure use in CMS' Part D quality programs. Medicare Part D star ratings. Available at: https://www. pqaalliance.org/medicare-part-d. Accessed August 17, 2020.

16. Ta JT, Erickson SC, Qiu W, Patel B V. Is there a relationship between Part D medication adherence and Part $C$ intermediate outcomes star ratings measures? J Manag Care Spec Pharm. 2016;22(7):787-95. Available at: https:// www.jmcp.org/doi/10.18553/jmcp.2016.22.7.787.

17. Lee SK, Kang B-Y, Kim H-G, Son Y-J. Predictors of medication adherence in elderly patients with chronic diseases using support vector machine models. Healthe Inform Res. 2013;19(1):33.

18. Jin HK, Kim YH, Rhie SJ. Factors affecting medication adherence in elderly people. Patient Prefer Adherence. 2016;10:2117-25.

19. Soumerai SB, Pierre-Jacques M, Zhang F, et al. Cost-related medication nonadherence among elderly and disabled Medicare beneficiaries: a national survey 1 year before the Medicare drug benefit. Arch Intern Med. 2006;166(17):1829-35.

20. Roumie CL. The doughnut hole: it's about medication adherence. Ann Intern Med. 2012;56(11):834-35.

21. Reinberg S. Nearly 1 in 10 adults skips meds due to cost, CDC says. HealthDay. January 29, 2015. Available at: https://consumer.healthday.com/ senior-citizen-information-31/misc-aging-news-10/nearly-1-in-10-adultsskips-meds-due-to-cost-cdc-says-695925.html. Accessed July 22, 2020.

22. Mishra SI, Gioia D, Childress S, Barnet B, Webster RL. Adherence to medication regimens among low-income patients with multiple comorbid chronic conditions. Heal Soc Work. 2011;36(4):249-58.

23. Gu Q, Zeng F, Patel BV, Tripoli LC. Part D coverage gap and adherence to diabetes medications. Am J Manag Care. 2010;16(12):911-18.

24. Medicare Rights Center. State pharmaceutical assistance programs. 2019. Available at: https://www.medicareinteractive.org/pdf/SPAP-Chart.pdf. Accessed July 22, 2020

25. Mäkelä MJ, Backer V, Hedegaard M, Larsson K. Adherence to inhaled therapies, health outcomes and costs in patients with asthma and COPD. Respir Med. 2013;107(10):1481-90.

26. Sokol MC, McGuigan KA, Verbrugge RR, Epstein RS. Impact of medication adherence on hospitalization risk and healthcare cost. Med Care. 2005;43(6):521-30.

27. Pittman DG, Tao Z, Chen W, Stettin GD. Antihypertensive medication adherence and subsequent healthcare utilization and costs. Am J Manag Care. 2010;16(8):568-76.

28. ProximityOne. 10 reasons to use Census Tract versus ZIP code. Available at: http://proximityone.com/tracts_zips.htm. Accessed July 22, 2020. 


\section{Association of Medication Adherence with Hospital Utilization and Costs Among Elderly with Diabetes Enrolled in a State Pharmaceutical Assistance Program}

29. Huber CA, Rapold R, Brüngger B, Reich O, Rosemann T. One-year adherence to oral antihyperglycemic medication and risk prediction of patient outcomes for adults with diabetes mellitus: an observational study. Medicine (Baltimore). 2016;95(26):e3994

30. Lin L-K, Sun Y, Heng BH, Chew DEK, Chong P-N. Medication adherence and glycemic control among newly diagnosed diabetes patients. BMJ Open Diabetes Res Care. 2017;5(1):e000429.

31. Ho P, Rumsfeld J. Effect of medication nonadherence on hospitalization and mortality among patients with diabetes mellitus. Arch Intern Med. 2006;166(17):1836-41

32. Ding J. Predictors and health outcomes of medication non-adherence across multiple therapeutic classes among elderly [dissertation]. University Park, PA: Pennsylvania State University; 2010. Available at: https://etda. libraries.psu.edu/files/final_submissions/3253. Accessed July 22, 2020.

33. Pennsylvannia Health Care Cost Containment Council. What is the Pennsylvania Health Care Cost Containment Council? 2019. Available at: http://www.phc4.org/council/mission.htm. Accessed July 22, 2020.

34. Pennsylvania Health Care Cost Containment Council. Services \& data requests - data available. Available at: http://www.phc4.org/services/ datarequests/data.htm. Accessed August 17, 2020.

35. Roberts AW, Crisp GD, Esserman DA, Roth MT, Weinberger M, Farley JF. Patterns of medication adherence and health care utilization among patients with chronic disease who were enrolled in a pharmacy assistance program. N C Med J. 2014;75(5):310-18.

36. Krumme AA, Franklin JM, Isaman DL, et al. Predicting 1-year statin adherence among prevalent users: a retrospective cohort study. J Manag Care Spec Pharm. 2017;23(4):494-502. Available at: https://www.jmcp.org/ doi/10.18553/jmcp.2017.23.4.494.

37. Pednekar PP, Agh T, Malmenas M, et al. Methods for measuring multiple medication adherence: a systematic review-report of the ISPOR Medication Adherence and Persistence Special Interest Group. Value Health. 2019;22(2):139-56.

38. Stolpe S, Kroes MA, Webb N, Wisniewski T. A systematic review of insulin adherence measures in patients with diabetes. J Manag Care Spec Pharm. 2016;22(11):1224-46. Available at: https://www.jmcp.org/ doi/10.18553/jmcp.2016.22.11.1224.

39. Qato DM, Daviglus ML, Wilder J, Lee T, Qato D, Lambert B. "Pharmacy deserts" are prevalent in Chicago's predominantly minority communities, raising medication access concerns. Health Aff (Millwood) 2014;33(11):1958-65.

40. Peterson AM, Nau DP, Cramer JA, Benner J, Gwadry-Sridhar F, Nichol M. A checklist for medication compliance and persistence studies using retrospective databases. Value Health. 2007;10(1):3-12.

41. Nau DP. Proportion of days covered (PDC) as a preferred method of measuring medication adherence. Pharmacy Quality Alliance. Available at: https://www.researchgate.net/publication/273505401_Cost-effectiveness Analysis_of_LDL_cholesterol-Lowering_Therapy_in_Hypertensive_ Patients_with_Type-2_Diabetes_in_Korea_Single-Pill_Regimen AmlodipineAtorvastatin_versus_Double-Pill_Regimen_Amlodipine_/ful ltext/55d8d67908aed6a199a88e96/Cost-effectiveness-Analysis-of-LDLcholesterol-Lowering-Therapy-in-Hypertensive-Patients-with-Type-2Diabetes-in-Korea-Single-Pill-Regimen-Amlodipine-Atorvastatin-versusDouble-Pill-Regimen-Amlodipine.pdf. Accessed July 22, 2020.

42. Choudhry NK, Shrank WH, Levin RL, et al. Measuring concurrent adherence to multiple related medications. Am J Manag Care. 2009;15(7):457-64.

43. Amin K, Farley JF, Maciejewski ML, Domino ME. Effect of Medicaid policy changes on medication adherence: differences by baseline adherence. J Manag Care Spec Pharm. 2017;23(3):337-45. Available at: https://www.jmcp. org/doi/10.18553/jmcp.2017.23.3.337.

44. Basak R, McCaffrey DJ III, Bentley JP, Przybyla SM, West-Strum D, Banahan BF. Adherence to multiple medications prescribed for a chronic disease: a methodological investigation. J Manag Care Pharm. 2014;20(8):815-23. Available at: https://www.jmcp.org/doi/10.18553/jmcp.2014.20.8.815.
45. Karve S, Markowitz M, Fu DJ, et al. Assessing medication adherence and healthcare utilization and cost patterns among hospital-discharged patients with schizoaffective disorder. Appl Health Econ Health Policy. 2014;12(3):335-46.

46. Akinbosoye OE, Taitel MS, Grana J, Hill J, Wade RL. Improving medication adherence and health care outcomes in a commercial population through a community pharmacy. Popul Health Manag. 2016;19(6):454-61.

47. Kim JA, Lim MK, Kim K, Park JH, Rhee CK. Adherence to inhaled medications and its effect on healthcare utilization and costs among highgrade chronic obstructive pulmonary disease patients. Clin Drug Investig. 2018;38(4):333-40.

48. Pilon D, Muser E, Lefebvre P, Kamstra R, Emond B, Joshi K. Adherence, healthcare resource utilization and Medicaid spending associated with oncemonthly paliperidone palmitate versus oral atypical antipsychotic treatment among adults recently diagnosed with schizophrenia. BMC Psychiatry. 2017;17(2):207.

49. Sheehan DV, Keene MS, Eaddy M, Krulewicz S, Kraus JE, Carpenter DJ. Differences in medication adherence and healthcare resource utilization patterns: older versus newer antidepressant agents in patients with depression and/or anxiety disorders. CNS Drugs. 2008;22(11):963-73.

50. Pednekar P, Peterson A. Mapping pharmacy deserts and determining accessibility to community pharmacy services for elderly enrolled in a state pharmaceutical assistance program. PLoS One. 2018;13(6):e0198173.

51. Roberts A, Crisp GD, Esserman DA, Roth MT, Weinberger M, Farley JF. Patterns of medication adherence and health care utilization among patients with chronic disease who were enrolled in a pharmacy assistance program. N C Med J. 2014;75(5):310-18.

52. Saberi P, Johnson MO, McCulloch CE, Vittinghoff E, Neilands TB Medication adherence: tailoring the analysis to the data. AIDS Behav. 2011;15(7):1447-53.

53. Deb P, Norton EC. Modeling health care expenditures and use. Annu Rev Public Health. 2018;39:489-505.

54. Lau DT, Nau DP. Oral antihyperglycemic medication nonadherence and subsequent hospitalization among individuals with type 2 diabetes. Diabetes Care. 2004;27(9):2149-53.

55. Curtis SE, Boye KS, Lage MJ, Garcia-Perez LE. Medication adherence and improved outcomes among patients with type 2 diabetes. Am J Manag Care. 2017;23(7):e208-e214.

56. Roebuck MC, Liberman JN, Gemmill-Toyama M, Brennan TA. Medication adherence leads to lower health care use and costs despite increased drug spending. Health Aff (Millwood). 2011;30(1):91-99.

57. Encinosa WE, Bernard D, Dor A. Does prescription drug adherence reduce hospitalizations and costs? The case of diabetes. Adv Health Econ Health Serv Res. 2010;22:151-73.

58. Kennedy-Martin T, Boye KS, Peng X. Cost of medication adherence and persistence in type 2 diabetes mellitus: a literature review. Patient Prefer Adherence. 2017;11:1103-17.

59. Ho PM, Rumsfeld JS, Masoudi FA, et al. Effect of medication nonadherence on hospitalization and mortality among patients with diabetes mellitus. Arch Intern Med. 2006;166(17):1836-41.

60. Boye KS, Curtis SE, Lage MJ, Garcia-Perez LE. Associations between adherence and outcomes among older, type 2 diabetes patients: evidence from a Medicare supplemental database. Patient Prefer Adherence. 2016;10:1573-81.

61. Ho PM, Magid DJ, Shetterly SM, et al. Importance of therapy intensification and medication nonadherence for blood pressure control in patients with coronary disease. Arch Intern Med. 2008;168(3):271-76.

62. Ray WA. Evaluating medication effects outside of clinical trials: newuser designs. Am J Epidemiol. 2003;158(9):915-20.

63. Dong YH, Choudhry NK, Krumme A, et al. Impact of hospitalization on medication adherence estimation in claims data. J Clin Pharm Ther. 2017;42(3):318-28. 
APPENDIX A Proportion of Patients Who Had at Least 1 Hospital Visit During the 12-Month Post-Index Observation Period, Overall and by Adherence Status $(N=9,497)$

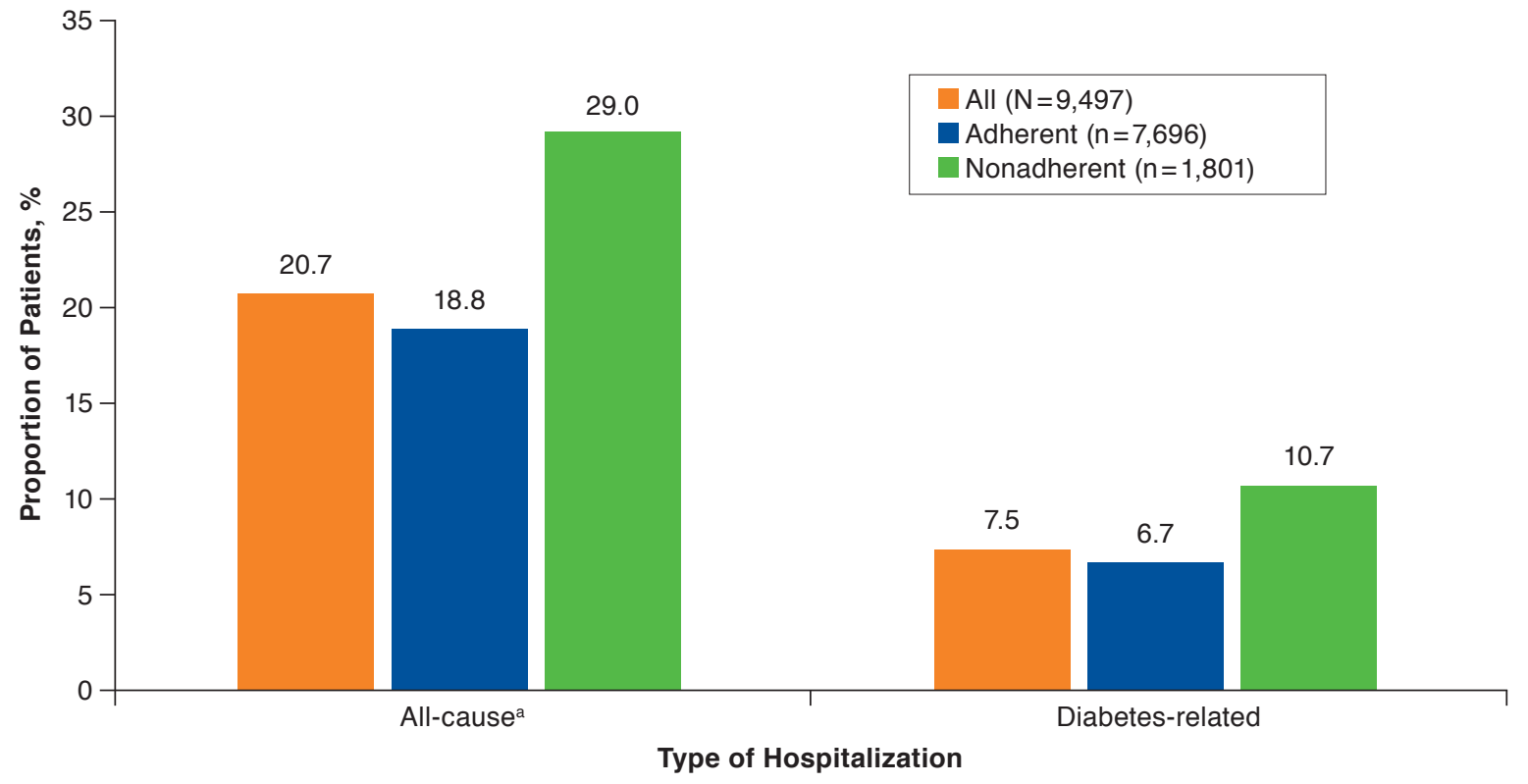


APPENDIX B Unadjusted Health Care Utilization and Costs Among Patients Who Had at Least 1 Hospital Visit During the 12-Month Post-Index Observation Period, Overall and by Adherence Status ${ }^{\mathrm{a}}$ $(\mathrm{N}=1,970)$

\begin{tabular}{|c|c|c|c|c|c|c|c|}
\hline $\begin{array}{l}\text { Health Care } \\
\text { Utilization/Cost Variable }\end{array}$ & \multicolumn{2}{|c|}{$\begin{array}{c}\text { All } \\
(\mathrm{N}=1,970)\end{array}$} & \multicolumn{2}{|c|}{$\begin{array}{c}\text { Adherent } \\
(\mathrm{PDC} \geq 80 \%) \\
(\mathrm{n}=1,448)\end{array}$} & \multicolumn{2}{|c|}{$\begin{array}{l}\text { Nonadherent } \\
(\mathrm{PDC}<80 \%) \\
(\mathrm{n}=522)\end{array}$} & $P$ Value $^{b}$ \\
\hline \multicolumn{8}{|c|}{ Number of inpatient hospital visits per 100 persons (SD) } \\
\hline All-cause & 164 & $(1.10)$ & 156 & $(0.94)$ & 188 & $(1.42)$ & $<0.0001$ \\
\hline Diabetes-related & 48 & $(0.76)$ & 47 & $(0.74)$ & 51 & $(0.82)$ & 0.2518 \\
\hline \multicolumn{8}{|c|}{ Length of stay in days, mean (SD) } \\
\hline All-cause & 8.68 & $(10.18)$ & 7.70 & $(8.56)$ & 11.41 & (13.34) & $<0.0001$ \\
\hline Diabetes-related & 2.06 & $(4.33)$ & 1.91 & $(4.01)$ & 2.47 & $(5.11)$ & 0.0254 \\
\hline \multicolumn{8}{|c|}{ Costs of inpatient hospitalizations, mean (SD)c } \\
\hline All-cause & $\$ 18,066$ & $\$ 21,611)$ & $\$ 16,266$ & $(\$ 18,323)$ & $\$ 23,059$ & $\$ 28,260)$ & $<0.0001$ \\
\hline Diabetes-related & $\$ 4,623$ & $\$ 10,262)$ & $\$ 4,477$ & $(\$ 9,933)$ & $\$ 5,029$ & $(\$ 11,124)$ & 0.3179 \\
\hline
\end{tabular}

${ }^{a}$ Differences between adherent and nonadherent patients were examined using $t$-tests.

bStatistically significant if $P<0.05$.

cPresented in 2015 U.S. dollars.

$P D C=$ proportion of days covered; $S D=$ standard deviation 